\title{
Metastatic Giant Cell Tumor of Bone
}

\author{
Are There Associated Factors and Best Treatment Modalities?
}

\author{
Seethalakshmi Viswanathan MD, N. A. Jambhekar MD, DPB
}

Received: 20 December 2008/Accepted: 19 June 2009/Published online: 14 July 2009

(C) The Association of Bone and Joint Surgeons (B) 2009

\begin{abstract}
Giant cell tumors of bone are sometimes locally aggressive and may metastasize, although uncommonly. We attempted to identify associations of clinical and histopathologic parameters with metastasis, the longterm outcome with metastases, and the best treatment. We identified distant metastases in 24 of 470 patients with giant cell tumors during a 20-year period. The median age of these 24 patients at presentation was 26 years (range, 16-76 years), and the male:female ratio was 1.6:1, with no predilection for primary site. Metastasis occurred at a mean of 2 years (range, 4 months-11 years) after initial diagnosis. Sites for distant metastases were the lung (21 of 24 patients), scalp, calf muscle, and regional lymph nodes. The 24 patients had a mean followup of 3.5 years (range, $0-16$ years). Thirteen of the 24 patients has local recurrence before or at the time of metastasis. Two patients refused treatment, eight underwent metastasectomy, and 14 were inoperable (four had chemotherapy, 10 were treated symptomatically). We observed disease progression with hemoptysis in one of 14 patients. None of the patients died of their metastatic disease. None of the risk factors we studied was associated with metastasis in giant cell tumors.
\end{abstract}

Each author certifies that he or she has no commercial associations (eg, consultancies, stock ownership, equity interest, patent/licensing arrangements, etc) that might pose a conflict of interest in connection with the submitted article.

Each author certifies that his or her institution has approved the human protocol for this investigation and that all investigations were conducted in conformity with ethical principles of research.

Seethalakshmi Viswanathan, N. A. Jambhekar $(\square)$

Department of Pathology, Tata Memorial Hospital, Parel,

Mumbai 400012, India

e-mail: najambhekar@rediffmail.com
Although the overall outcome was favorable, metastasectomy is recommended where feasible.

Level of Evidence: Level IV, therapeutic study. See Guidelines for Authors for a complete description of levels of evidence.

\section{Introduction}

Metastasis in giant cell tumor (GCT) of bone occurs most commonly in the lung, variously reported from $1 \%$ to $9 \%$ $[7,9,17,19,20]$. There have been isolated case reports of its occurrence at different sites, such as the lymph nodes (mediastinum, paraaortic), bone, skin, and breast [1, 6, 9, $13,14,21]$. However, awareness of the metastatic potential of these tumors has increased, and improved methods of detection have led to their increased recognition [9].

Authors have suggested several etiologies and mechanisms of metastasis in GCT including transformation from a self-limited benign course and true arterial metastasis $[4,8,15,16,18]$. Postulated mechanisms could be either embolism or active "biologic predeterminism" of the giant cells to invade the interstitium, destroy vessel walls, and intravasate by means of enzymes with subsequent lodgment and growth in target organs [4]. There also is debate regarding whether surgical manipulation promotes pulmonary metastasis $[4,8,15,16,18]$.

There is currently no definitive method to predict distant metastasis in GCT based on histology or flow cytometry [12]. Their growth rate (as measured by doubling time) is extremely low, supporting the concept that these probably were present at the time of initial resection and took years to become radiographically recognizable [10]. Reported potential risk factors for metastasis in GCT [7, 17, 19, 20] include the primary site, local recurrences, and modality 
of treatment of the primary tumor. The literature contains only reports of surgically resected cases and none seeking to explore the best treatment for metastatic GCT.

We therefore (1) asked whether any of the above-mentioned factors were associated with metastasis and (2) assessed the eventual outcome associated with these factors and treatment choice after a long followup.

\section{Materials and Methods}

We retrospectively retrieved data from medical records and pathology reports of patients treated for bone tumors between 1987 and 2006. Five hundred eighty-seven cases of GCT of bone were diagnosed among 7500 bone tumors reported in our pathology department. We excluded 101 cases referred for pathology consultation only (without clinicoradiographic details) and 16 cases in which the diagnosis subsequently was revised. We identified 24 patients $(5.1 \%)$ with metastasis of GCT to various locations from the remaining 470 cases. Details of the clinicoradiographic profile were abstracted from the patients' charts. The clinicoradiographic profile included age, gender, duration of symptoms, radiographic findings, details of primary surgical treatment, and followup details such as occurrence of local recurrence and metastasis, duration from primary treatment, therapeutic management of the metastasis, and followup until the patient last visited the hospital. Owing to the rarity of metastasis in GCT and the small sample size, we were unable to statistically determine whether any of the above factors was a risk to predict the possibility of metastasis in GCT.

The median age of the patients was 26 years (range, 16-76 years); 17 (70.8\%) patients were between 20 and 30 years and 14 (58.3\%) were between 25 and 30 years
(Tables 1,2). Males slightly predominated over females (males:females, 1.6:1). Of the 24 patients, 21 had metastasis in the lung and one each had metastasis in the inguinal lymph node, scalp, and calf muscles. Of these, eight patients had metastasectomy and histologic confirmation whereas the other 16 patients were not treated surgically and had no histologic confirmation. Two of the 24 patients were lost to followup after being diagnosed with metastasis and therefore did not receive any treatment. The eight patients who had metastasectomy had a minimum followup of 1 year after surgery (mean, 1.8 years; range, 1-3 years). The 14 remaining patients who either received chemotherapy (four patients) or were treated symptomatically (10 patients) had a minimum followup of 1 month (mean, 2 years; range, 1 month-16 years. The two groups, nonmetastasectomy and metastasectomy, were analyzed separately.

In the nonmetastasectomy group, there were 16 patients with a median age of 27 years (range, 17-76 years); 11 of these patients were between 25 and 30 years. Males slightly predominated (males:females, 1.1:1). Four patients with pulmonary metastasis had symptoms in the form of hemoptysis owing to a large central metastatic nodule communicating with the bronchus $(\mathrm{n}=2)$, chest pain $(\mathrm{n}=1)$, and symptoms of bronchial obstruction (cough and dyspnea) $(\mathrm{n}=1)$; the metastases in the remaining 12 patients were detected on routine followup. Two patients had single metastatic lesions whereas the remaining 14 had multiple lesions. In one patient, the lesion was a single large mass infiltrating the adjacent chest wall and mediastinal structures with pericardial effusion. One patient had pleural metastasis in addition to involvement of the pulmonary parenchyma. Long bones were involved in 13 cases. The other bones involved were small bones of the hand (two cases) and pelvis (one case). Treatment of the

Table 1. Clinical profile of patients with GCT with lung metastases in the metastasectomy group

\begin{tabular}{|c|c|c|c|c|c|c|c|}
\hline Patient & $\begin{array}{l}\text { Age } \\
\text { (years) }\end{array}$ & Gender & Location of primary & $\begin{array}{l}\text { Treatment } \\
\text { of primary lesion }\end{array}$ & Local recurrence/Interval & $\begin{array}{l}\text { Interval to } \\
\text { metastasis }\end{array}$ & $\begin{array}{l}\text { Treatment } \\
\text { of metastases }\end{array}$ \\
\hline 1 & 32 & Male & Tibia, upper end & Wide excision & Nil & 11 years & $\begin{array}{l}\text { Metastatectomy } \\
\quad+\text { chemotherapy }\end{array}$ \\
\hline 2 & 25 & Male & Humerus, upper end & Wide excision & Nil & 1 year & Metastatectomy \\
\hline 3 & 25 & Male & Tibia, upper end & Wide excision & Once at 15 months & 3 years & Metastatectomy \\
\hline 4 & 16 & Male & Tibia, upper end & Wide excision & Nil & 5 months & Metastatectomy \\
\hline 5 & 26 & Female & Femur, lower end & Amputation & Once at 10 months & 12 months* & Metastatectomy \\
\hline 6 & 21 & Female & Femur, lower end & Wide excision & Nil & At presentation* & Metastatectomy \\
\hline 7 & 26 & Male & Pelvis & Hemipelvectomy & Nil & 6 months* & Metastatectomy \\
\hline 8 & 20 & Female & Forefinger & Amputation & Nil & $2 \mathrm{yrs}$ & $\begin{array}{l}\text { Metastatectomy } \\
+ \text { chemotherapy }\end{array}$ \\
\hline
\end{tabular}

* Patients 5, 6, and 7 had metastasis to the inguinal lymph node, scalp, and calf muscle; GCT = giant cell tumor. (Reprinted with permission from Gupta R, Seethalakshmi V, Jambhekar NA, Prabhudesai S, Merchant N, Puri A, Agarwal M. Clinicopathologic profile of 470 giant cell tumors of bone from a cancer hospital in western India. Ann Diagn Pathol. 2008;12:239-248.) 
Table 2. Clinical profile of patients with GCT with lung metastases in the nonmetastasectomy group

\begin{tabular}{|c|c|c|c|c|c|c|c|}
\hline Patient & $\begin{array}{l}\text { Age } \\
\text { (years) }\end{array}$ & Gender & $\begin{array}{l}\text { Location } \\
\text { of primary }\end{array}$ & $\begin{array}{l}\text { Treatment } \\
\text { of primary }\end{array}$ & $\begin{array}{l}\text { Local recurrence/ } \\
\text { Interval }\end{array}$ & $\begin{array}{l}\text { Interval to } \\
\text { metastasis }\end{array}$ & $\begin{array}{l}\text { Treatment } \\
\text { of metastases }\end{array}$ \\
\hline 1 & 30 & Male & Radius, lower end & $\begin{array}{l}\text { Excision }+ \text { radiation } \\
\text { therapy }\end{array}$ & Once at 12 months & 3 years & Symptomatic \\
\hline 2 & 25 & Female & $\begin{array}{l}\text { Upper end of tibia } \\
\text { and fibula }\end{array}$ & $\begin{array}{l}\text { Intralesional } \\
\text { margins }+ \text { radiation } \\
\text { therapy }\end{array}$ & Once at 7 months & 3 years & Symptomatic \\
\hline 3 & 76 & Female & Proximal phalanx & Amputation & Once at 18 months & 7 years & Symptomatic \\
\hline 4 & 30 & Male & Pubis & Curettage & Nil & 1 year & Chemotherapy \\
\hline 5 & 26 & Male & Femur, lower end & Wide excision + TKA & Once at 18 months & 1.5 years & $\begin{array}{l}\text { Symptomatic } \\
\text { (16-year } \\
\text { followup) }\end{array}$ \\
\hline 6 & 26 & Female & Metacarpal & Amputation & Once at 4 months & 2 years & Chemotherapy \\
\hline 7 & 28 & Female & Tibia, upper end & Amputation & Once at 8 months & 1 year & Symptomatic \\
\hline 8 & 26 & Male & Radius, lower end & Amputation & Nil & At presentation & Symptomatic \\
\hline 9 & 25 & Male & Tibia, upper end & Wide excision & Once at 5 months & 3 years & Chemotherapy \\
\hline 10 & 45 & Female & Tibia, upper end & Wide excision & Once at 4 months & 9 months & Lost to followup \\
\hline 12 & 30 & Male & Radius, lower end & Amputation & $\begin{array}{l}\text { Twice at } 11 \text { months } \\
\text { and } 19 \text { months }\end{array}$ & 2 years & Symptomatic \\
\hline 13 & 17 & Female & Radius, lower end & Amputation & $\begin{array}{l}\text { Twice at } 6 \text { months } \\
\text { and } 9 \text { months }\end{array}$ & 1.5 years & Symptomatic \\
\hline 14 & 48 & Female & Femur, lower end & Curettage & Nil & At presentation & Lost to followup \\
\hline 15 & 27 & Male & Femur, lower end & Amputation & Nil & 2 years & Chemotherapy \\
\hline 16 & 32 & Male & Humerus, upper end & Amputation & Once at 12 months & At presentation & Symptomatic \\
\hline
\end{tabular}

(Reprinted with permission from Gupta R, Seethalakshmi V, Jambhekar NA, Prabhudesai S, Merchant N, Puri A, Agarwal M. Clinicopathologic profile of 470 giant cell tumors of bone from a cancer hospital in western India. Ann Diagn Pathol. 2008;12:239-248.)

primary tumor consisted of curettage in three cases, wide excision in four cases, and amputation in nine cases. These patients did not undergo metastasectomy for their lung metastasis either because they were inoperable or they refused treatment. Four patients received chemotherapy for metastasis, 10 received symptomatic treatment only, and two were lost to followup after diagnosis of their metastasis.

In the metastasectomy group of eight patients, the median age was 25 years (range, 16-32 years); six patients were between 20 and 26 years. Males predominated and were three times as common as females. The metastases in all these patients were detected on routine followup. The primary lesion most commonly was located in the long bones (six cases). The other bones involved were small bones of the hand (one case) and pelvis (one case). Four patients had a single metastatic lesion seen on chest radiograph/CT scan whereas four patients had multiple bilateral metastatic lesions scattered throughout the lung parenchyma (Fig. 1). Single metastatic lesions were observed in the scalp and calf muscle whereas multiple metastatic lesions involved the inguinal nodes in a case of GCT of the femur.

The primary tumor was treated by wide excision in six cases and by amputation in two. Local recurrence at the

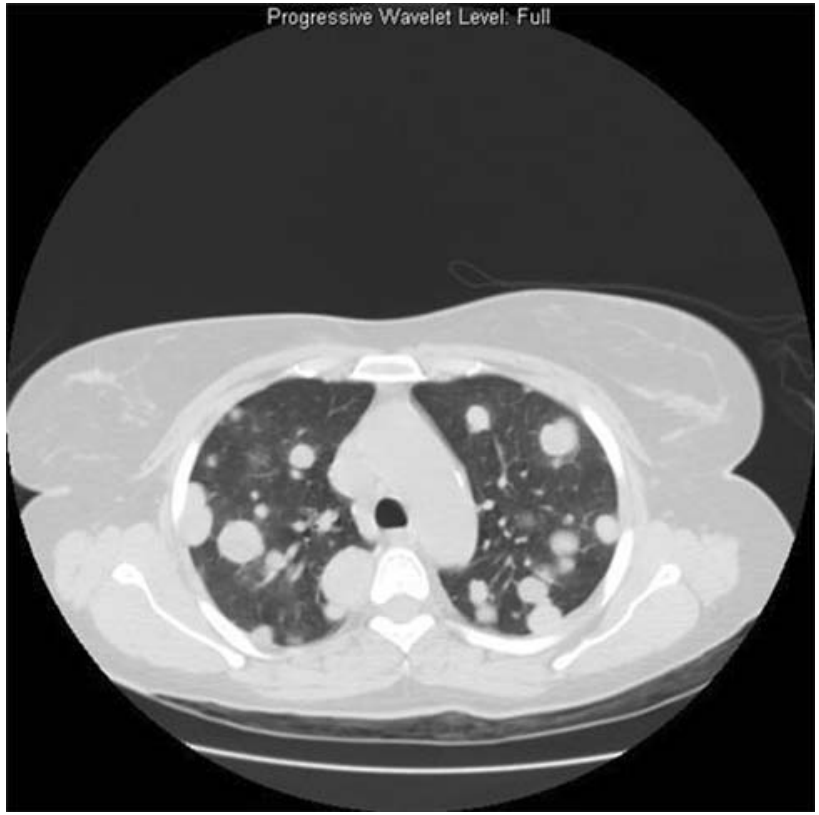

Fig. 1 A CT scan of the chest shows multiple bilateral pulmonary metastases of GCT of bone.

primary site was seen in two of the eight patients and metastasis was detected within 2 months and 2 years of the local recurrence. None of the patients had multiple local 
recurrences. Metastasectomies were performed in all three patients with single metastatic lesions in the scalp and calf muscle and multiple metastatic lesions involving inguinal nodes in a case of GCT of the femur and pelvis; therefore, all of these were histologically confirmed.

No predilection was observed for involvement of any particular lobe of the lung in both groups. The metastatic nodules ranged from $0.3 \mathrm{~cm}$ to $7 \mathrm{~cm}$. Radiographically, they were nodular, rounded, well-defined opacities (Fig. 1). The larger lesions had solid and cystic areas in the nodules. All these cases were benign GCT on primary histologic analysis. No case of malignant GCT was observed in this series.

We retrieved histologic specimens of the primary bone tumor for all 24 patients with radiographically documented metastasis and metastasectomy specimens of the eight patients who underwent surgical excision of their metastatic lesions. The material included fresh tissue or a combination of specimens, paraffin blocks, and slides of either the primary or recurrent tumors in patients referred to the hospital for further management. The histologic specimens in all cases were reviewed and the diagnoses confirmed by two independent pathologists (SV, NAJ), one of whom has extensive experience in bone pathology. In the eight metastasectomy specimens, the gross appearance of the metastatic nodules was yellow-tan variegated with hemorrhage and necrosis (Fig. 2). The histologic features of the metastatic lesions were identical to those of the primary tumors, which all were typical of the usual GCT of

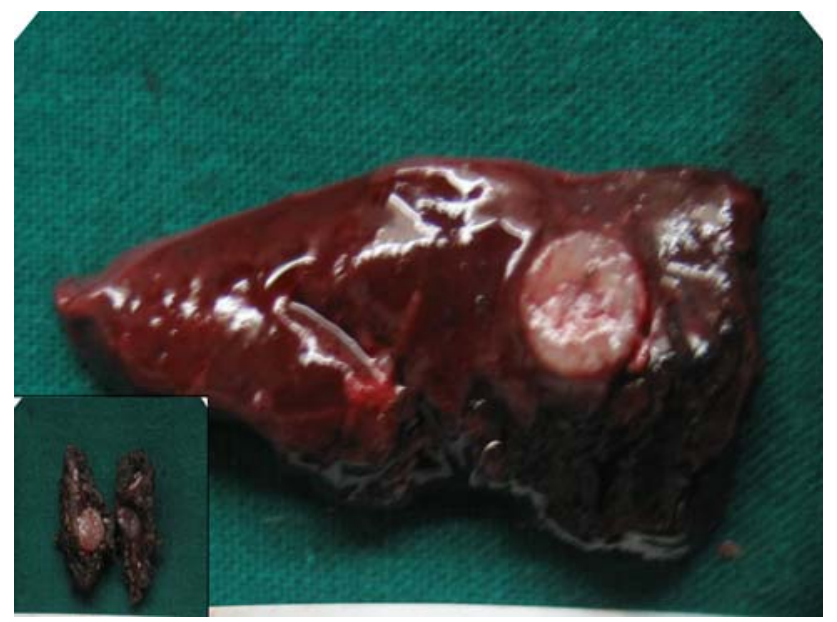

Fig. 2 Multiple lung metastasectomy specimens are shown. All specimens have a well-circumscribed fleshy nodule. The inset shows two other smaller nodules resected from the same patient. The histologic features of these lung nodules were identical to the classic histologic features of the primary tumor in the upper end of the tibia. (Reprinted with permission from Gupta R, Seethalakshmi V, Jambhekar NA, Prabhudesai S, Merchant N, Puri A, Agarwal M. Clinicopathologic profile of 470 giant cell tumors of bone from a cancer hospital in western India. Ann Diagn Pathol. 2008;12: 239-248.) bone (Figs. 3, 4). The tumors had numerous multinucleate giant cells uniformly scattered in a spindle cell stroma together forming a syncytium-like sheet. In addition, routine features seen in GCTs such as osteoid, fibrosis, collagenization, ectatic blood channels, sheets of stromal cells, and focal storiform pattern also were noted. There was no evidence of any atypical features: no anaplasia or atypical mitosis observed in the primary, recurrent, or metastatic lesions.

\section{Results}

We observed no obvious association in either group between occurrence of metastasis and histopathologic or clinical risk factors such as site of the primary tumor, local recurrences, and modality of treatment of the primary tumor. In the nonmetastasectomy group, of the 16 patients, three had metastasis at presentation whereas the rest had metastasis develop from 9 months to 3 years after treatment of the primary tumor. Except for one patient who had metastasis after 7 years, 15 patients had metastases within 3 years after primary treatment. Local recurrence at the primary site was seen in 11 of 16 cases 4 months to 18 months after primary treatment; two had two recurrences. Metastasis occurred 2 months to 5 years after the local recurrence except in one patient in whom metastasis was detected at presentation. In the metastasectomy group, one patient had metastasis at presentation whereas the rest had metastasis develop 5 months to 11 years after treatment of primary disease. Local recurrence at the primary site was seen in two of the eight patients and metastasis was detected within 2 months and 2 years of the local recurrence.

The overall outcome of metastatic GCT was favorable in this series and none of the patients died of metastatic disease regardless of whether they had metastasectomy, chemotherapy, or symptomatic treatment up to their last followup. One patient treated symptomatically had progressively increasing lesions during a 1-year period with breathlessness and then had a large central lesion develop that communicated with the bronchus with hemoptysis. Another patient with multiple pleural lesions who had a followup of 5 years was asymptomatic. The patient with the longest followup of 16 years was a 26 -year-old man with a GCT at the lower end of femur, which was excised in 1991. A year and a half later in 1992, the patient had local recurrence with simultaneous bilateral lung metastases. A TKA was performed and only symptomatic treatment was offered for the metastatic lesions. At the last followup in 2008, the patient had complete resolution at the primary site and the metastatic lesions were still asymptomatic with no increase in size. 
Fig. 3A-C The photomicrographs show metastasis of a GCT to (A) an inguinal lymph node (Stain, hematoxylin and eosin; original magnification, $\times 100$ ), and (B) scalp tissue (Stain, hematoxylin and eosin; original magnification, $\times 40)$. $(\mathbf{C})$ A photomicrograph shows an intravascular lymphatic embolus composed of stromal cells at the periphery of the lymph node (Stain, hematoxylin and eosin; original magnification, $\times 200$ ) . (Reprinted with permission from Gupta R, Seethalakshmi V, Jambhekar NA, Prabhudesai S, Merchant N, Puri A, Agarwal M. Clinicopathologic profile of 470 giant cell tumors of bone from a cancer hospital in western India. Ann Diagn Pathol. 2008;12:239248.)
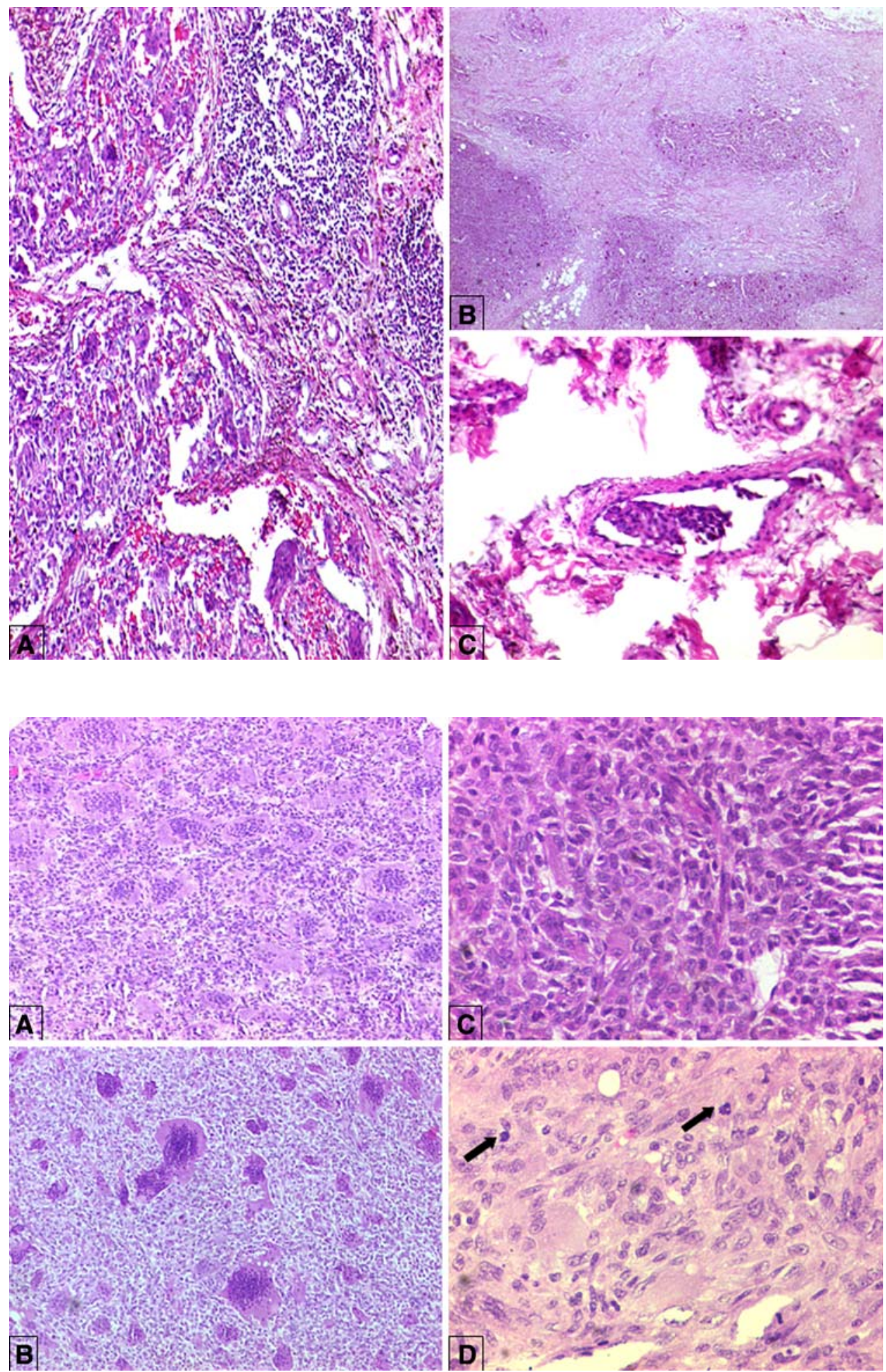

\section{Discussion}

GCTs of bone are regarded as aggressive and the most unpredictable neoplasms of the skeletal system, which can metastasize despite their innocent appearance [7, 9, 17, 19, 20]. There currently is no definitive method of predicting distant metastasis in GCT based on histology or flow cytometry [12]. We therefore explored the association, if any, between variably reported factors with metastasis in GCT $[7,9,17,19,20]$, such as site of primary tumor, duration and number of local recurrences, and treatment of primary tumor, assessed their outcome after a long 
followup, and evaluated the optimum therapeutic modality for management.

The major limitation of the study is the relatively small number of patients with metastatic GCT. Therefore the role of various factors predicting long-term outcome and their statistical significance could not be evaluated. A second limitation is that although stringent radiographic criteria have been used to identify metastases, not all lesions were histologically verified. However, this series includes all radiographically detected operable and inoperable metastatic lesions in contrast to other reported series of the same subject $[7,9,17,19,20]$. Many of the inoperable patients were treated symptomatically and therefore were followed up over the natural course of these presumed metastatic lesions.

The incidence of metastasis $(5.1 \%)$ in our patients is similar to reported incidences (1\%-9\%) [7, 9, 17, 19, 20]. All the pulmonary metastases seen were parenchymal, although endobronchial metastases rarely have been described [3]. The median age of the patients at presentation in this study was 26 years, peaking between 25 and 30 years, similar to other reports $[19,20]$ (Table 3 ). The slight male predominance (males:females, 1.6:1) seen in our patients is in contrast to the modest female predominance reported in the literature [19]. Similar to other reports $[19,20]$, we found age and gender did not predict metastasis. Although four of our patients had symptoms, most pulmonary lesions were asymptomatic and detected on routine followup [20]. The reported interval between diagnosis of the primary tumor and detection of metastases ranges from 0 to 10 years (average, 3.5 years) $[7,9,17,19$, 20], similar to our study in which metastasis was observed at 0 to 11 years (mean, 2 years) after the primary tumor. In 22 patients, metastasis occurred within 3 years of primary presentation. However, isolated cases of longer intervals of as much as 24 years have been reported [19]. Common primary sites with a predilection for metastasis include the radius, followed by the femur and sacrum $[19,20]$. We observed no predilection for metastasis in any particular bone, including the sacrum, which frequently is reported to be associated with metastasis $[19,20]$. Locally aggressive disease, multiple recurrences, and distal radius as the primary site have been associated with increased incidence of metastasis in GCT [11, 15, 19, 20]. We observed no such association. Thirteen patients had metastasis after local recurrence. The other 11 patients who had no local recurrence had their primary tumor resected with adequate margins; nine of these patients presented with metastasis 6 months to 2 years after primary treatment. One patient with metastasis 11 years after primary treatment also had no local recurrence. Occurrence of lung metastasis is known even without previous surgery on the primary tumor $[15,16]$, and this was observed in four of our

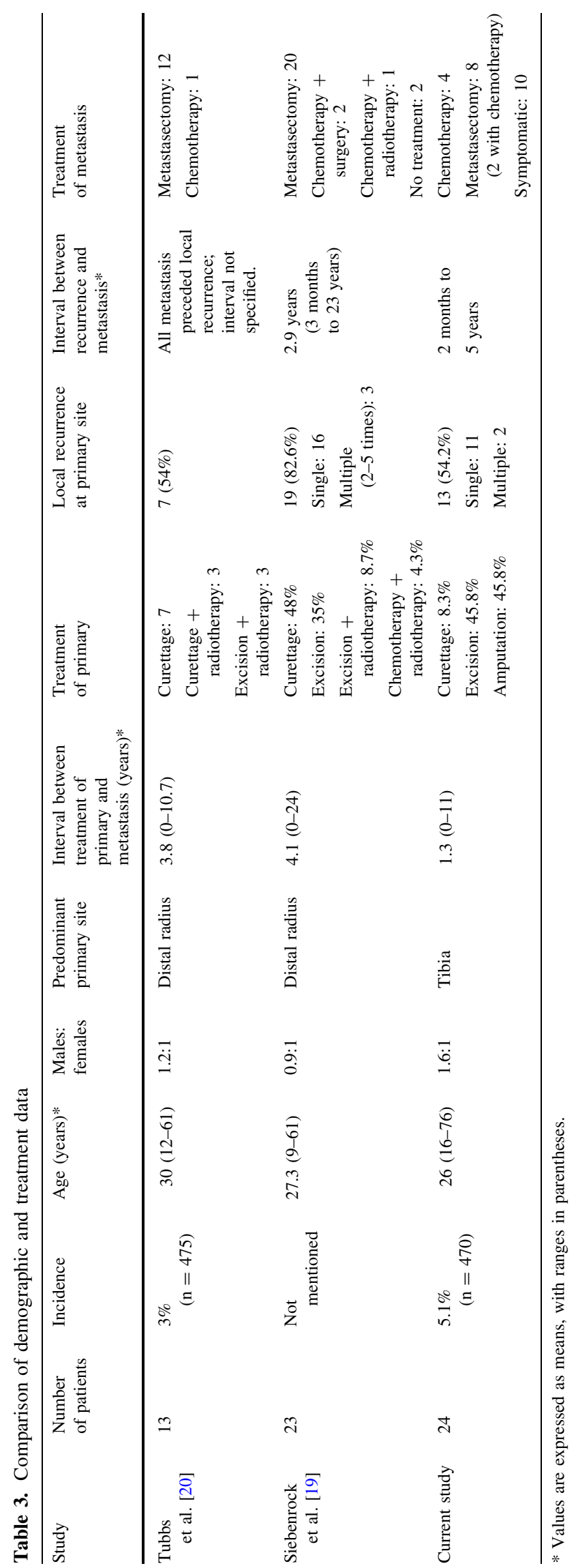


patients, where metastasis was detected at primary presentation. Histologic features of all the primary tumors associated with metastasis were identical to those of the tumors that did not metastasize. In patients who underwent metastasectomy, the histomorphologic features of the metastatic nodules were identical to those of the primary and recurrent lesions in terms of cellularity, abundance of osteoid, anaplasia, and the number of mitotic figures. No atypical mitotic figures were seen in any of the primary or metastatic lesions. Bertoni et al. [2] documented a metastatic rate of $40 \%$ in primary malignant GCTs. However, they also reported primary malignant GCTs that did not metastasize on long-term followup [2]. This finding is similar to the case of malignant GCT reported by Gupta et al. [9], which did not metastasize in the 3 years of documented followup.

None of the patients in our study died owing to their metastatic disease regardless of whether they had metastasectomy, chemotherapy, or symptomatic treatment. The longest followup in our series was 16 years, and the patient had no treatment for his metastatic lesions and is alive and doing well. However, the nature of these pulmonary metastases remains unpredictable as evidenced by reports of death caused by pulmonary failure $[19,20]$. One of the patients in our series who had inoperable disease had progression of his pulmonary lesions with worsening of symptoms and development of hemoptysis.

Although the general consensus is that patients with persistent untreated pulmonary metastases of GCT of bone have a good long-term prognosis and excellent survival rate $[5,7,9,11,17,19,20]$, we stress the importance of early detection of metastasis in GCT with regular longterm followup and recommend, where possible, appropriate surgical resection, such as metastasectomy, wedge resection, or lobectomy, to prevent progressive pulmonary dysfunction. However, we agree these patients should not receive aggressive radiation or chemotherapy as their overall prognosis and outcome are favorable.

\section{References}

1. Alacacioglu A, Bengi G, Oztop I, Canda T, Balci P, Osma E, Yilmaz U. Metastasis of giant cell tumor to the breast: case report and review of the literature. Tumori. 2006;92:351-353.

2. Bertoni F, Bacchini P, Staals EL. Malignancy in giant cell tumors of bone. Cancer. 2003;97:2520-2529.

3. Boghani A, Gayathri K, Ratnakar KS. Endobronchial metastasis from giant cell tumor of bone. Chest. 1994;106:1599-1601.
4. Caballes RL. The mechanism of metastasis in the so-called "benign giant cell tumor of bone". Hum Pathol. 1981;12:762767.

5. Cheng JC, Johnston JO. Giant cell tumor of bone: prognosis and treatment of pulmonary metastasis. Clin Orthop Relat Res. 1997;338:205-214.

6. Connell D, Munk PL, Lee MJ, O'Connell JX, Janzen D, Vu M, Masri BA. Giant cell tumor of bone with selective metastases to mediastinal lymph nodes. Skeletal Radiol. 1998;27:341-345.

7. Dominkus M, Ruggieri P, Bertoni F, Briccoli A, Picci P, Rocca M, Mercuri M. Histologically verified lung metastases in benign giant cell tumours: 14 cases from a single institution. Int Orthop. 2006;30:499-504.

8. Goldenberg RR, Campbell CJ, Bonfiglio M. Giant-cell tumor of bone: an analysis of two hundred and eighteen cases. J Bone Joint Surg Am. 1970;52:619-664.

9. Gupta R, Seethalakshmi V, Jambhekar NA, Prabhudesai S, Merchant N, Puri A, Agarwal M. Clinicopathologic profile of 470 giant cell tumors of bone from a cancer hospital in western India. Ann Diagn Pathol. 2008;12:239-248.

10. Katz E, Nyska M, Okon E, Zajicek G, Robin G. Growth rate analysis of lung metastases from histologically benign giant cell tumor of bone. Cancer. 1987;59:1831-1836.

11. Kay RM, Eckardt JJ, Seeger LL, Mirra JM, Hak DJ. Pulmonary metastasis of benign giant cell tumor of bone: six histologically confirmed cases, including one of spontaneous regression. Clin Orthop Relat Res. 1994;302:219-230.

12. Ladanyi M, Traganos F, Huvos AG. Benign metastasizing giant cell tumors of bone: a DNA flow cytometric study. Cancer. 1989;64:1521-1526.

13. Notarianni C, Abreo F, Nanda A. Cranial vault metastasis of giant cell tumor. Ann Diagn Pathol. 2008;12:286-289.

14. Present DA, Bertoni F, Springfield D, Braylan R, Enneking WF. Giant cell tumor of bone with pulmonary and lymph node metastases: a case report. Clin Orthop Relat Res. 1986;209:286290.

15. Rock M. Curettage of giant cell tumor of bone: factors influencing local recurrences and metastases. Proceedings of Combined European Musculoskeletal Oncology Society and Musculoskeletal Tumor Society Meeting. Bologna, Italy: Capelli Editore; 1989:204-205.

16. Rock M, Capanna R. The treatment of giant cell tumor of bone. In: Stauffer RN, ed. Advances in Operative Orthopaedics. Vol 1. St Louis, MO: Mosby-Year Book Inc; 1993:367-390.

17. Rock MG, Pritchard DJ, Unni KK. Metastases from histologically benign giant cell tumor of bone. J Bone Joint Surg Am. 1984;66:269-274.

18. Sanerkin NG. Malignancy, aggressiveness, and recurrence in giant cell tumor of bone. Cancer. 1980;46:1641-1649.

19. Siebenrock KA, Unni KK, Rock MG. Giant-cell tumour of bone metastasising to the lungs: a long-term follow-up. J Bone Joint Surg Br. 1998;80:43-47.

20. Tubbs WS, Brown LR, Beabout JW, Rock MG, Unni KK. Benign giant-cell tumor of bone with pulmonary metastases: clinical findings and radiologic appearance of metastases in 13 cases. AJR Am J Roentgenol. 1992;158:331-334.

21. Tyler W, Barrett T, Frassica F, MacCarthy E. Skin metastasis from conventional giant cell tumor of bone: conceptual significance. Skeletal Radiol. 2002;31:166-170. 